Review article

Paediatrics Today 2013;9(2):145-157

DOI $10.5457 / \mathrm{p} 2005-114.69$

\title{
NEUROBIOLOGY OF VIOLENCE IN CHILDREN AND ADOLESCENTS
}

\author{
Nataša ŠIMIĆ
}

Department of Psychology

University of Zadar

Zadar, Croatia

Corresponding author:

Nataša Šimić

Department of Psychology

University of Zadar

23000 Zadar

Croatia

nsimic04@gmail.com

Tel.: + 38523200568

Fax.: + 38523200685

Received: December 29, 2013

Accepted: April 17, 2013

Copyright (C) 2013 by University Clinical Center Tuzla. E-mail for permission to publish: paediatricstoday@ukctuzla.ba

\section{Introduction}

Neurobiological studies, which examine how the interaction of different parts of the nervous system, neurotransmitters and hormones contributes to human behaviour, are now one of the most developed and dynamic fields of research. Progress in study designs, imaging techniques and animal models has also led to an expansion in the knowledge and understanding of the neurobiological structures, chemicals, circuits and systems that regulate the expression of violence (1). Different social or economic causes of violence are well known, but more recently the awareness has grown of biological factors,
This paper gives a brief insight into the basic concepts of biological theories of personality with the purpose of understanding the personality profile of risk for antisocial behaviour in children and adolescents. The interest for the biological processes underlying the different personality traits and psychopathology in children and adolescents has increased in recent years. Therefore, the aim of this review is to summarize the results of the previous studies on the role of the personality and following neurobiological systems: testosterone, hypothalamic-pituitary-adrenal gland axis, autonomic nervous system and monoamine neurotransmitters in violent behaviour in children and adolescents. The effect of interaction of different biological and psychosocial factors, possible interpretations, as well as directions for further investigations are also pointed out. Conclusion - Biological processes play a key role in the genesis of violent behaviour. However, further research should also take into consideration the complexity of their interactive Key words: Antisocial behaviour - Testosterone - Cortisol - Autonomic nervous system - Monoamines.

which may also explain individual differences in predisposition to violence (2). According to Loeber and Pardini (3), neurobiological studies often share a number of implicit or explicit hypotheses about violence. Firstly, individuals differ in their propensity to commit violence. Aggression and violent behaviour also have elements in common with personality traits. Secondly, the underlying causes of violent behaviour are attributed to neurobiological factors. Biological parameters associated with antisocial behaviour include different components of the central nervous, autonomic and endocrine system. At the same time, many adverse environment factors that are traditionally thought to be 
social, may reflect genetic vulnerability (2). In addition, antisocial behaviour is viewed within a developmental context, beginning with gene expression in the embryo and continuing throughout the lifespan (1). Some authors (4) also emphasize that children's antisocial behaviour would ultimately indicate which individuals are most at risk, which types of interventions are likely to be most beneficial, and which individuals are most likely to benefit from intervention.

The basic concepts of the biological theory of personality presented in the first part of this paper should help in understanding the construct of arousal, as well as personality profiles of risk for violent behaviour. As a dynamic organization of biological systems that create specific patterns of behaviour, emotions and thoughts, personality allows prognosis of different behaviours and responses, including different forms of antisocial behaviour. Moreover, low fear of punishment and physiological hypoarousal may predispose individuals to seek out stimulation or take risks, and may also help to explain poor conditioning and socialization (4).

Different studies have shown a pattern of endocrine, psychophysiological and neurotransmitter reactions in individuals at risk for antisocial behaviour. The primary purpose of this paper is to summarize the results of previous studies on the role of personality following neurobiological systems: testosterone, hypothalamic-pituitary-adrenal gland (HPA) axis, autonomic nervous system and monoamine neurotransmitters in the violent behaviour in children and adolescents.

\section{The construct of arousal}

Although activation has been a construct often used in contemporary psychology, it has not yet been unambiguously defined. It usually implies a state of general arousal, which can vary along a continuum. At one end of the continuum there are conditions such as coma, deep sleep and relaxation, while the conditions of maximum excitation presenting with strong affects are at the other end of the continuum. The term arousal has often been identified with the concept of activation, but at a physiological level it is defined as increasing excitation of the central nervous structures, accompanied by an increase in the tone of the major part of the nervous system (5). Some authors (6) treat arousal as a one-dimensional construct. However, the low correlation between various indicators of activation level in the body have led to assumptions about the two-way nature of activation. Autonomous endocrine activation is based on changes in the functioning of the autonomic nervous and endocrine system. Another type is cortical activation, associated with the functioning of the ascending reticular activating system (ARAS). Stimulated by nerve impulses from sensory modalities, ARAS regulates cortical activation. The increased activity of the ARAS results in the synchronization of brain electrical activity, which is considered as a major indicator of cortical activation level (7). As indicators of the activation level of the organism, different activity indicators of the autonomic system (heart rate, blood pressure, electrodermal response (EDR) and the endocrine system, especially the adrenal glands, are also used. A considerable number of researchers prefer physiological measures, due to the poor reliability and validity of introspective reports, which can be influenced by social constraints and personal defence mechanisms. Measurements of physiological reactions have mostly been limited to laboratory studies. However, by miniaturization of instruments, an increasing number of studies in realistic situations use both psychological and physiological parameters. Although EEG, EDR and different parameters of cardiac activity (heart rate variability, for example) are the most commonly 
used measures, other measures that include biochemical analysis of blood or saliva have been shown to be very useful. Thus, testosterone, cortisol and other steroids can still be extracted from a saliva sample. Monoamine oxidase (also known as $\mathrm{MAO}$ ) is an enzyme that can also be measured in the blood (8). Differences in physiological reactions contribute to differences in psychological functioning. For example, people differ considerably in how much their nervous system is aroused in the same situation, under the same stimulation. EDR provides a direct measure of sympathetic nervous activity, which prepares the body for the fight-flight response. EDR can be triggered by various stimuli, including sudden sounds, images with charged emotional content, etc. However, some people have higher conductivity of the skin in the absence of external stimulation. For example, anxious and neurotic subjects have higher levels of sympathetic nervous activity. Increased heart rate also refers to the preparation of the body for the fight-flight reaction (8).

\section{The construct of arousal in biological theories of personality}

The concept of arousal is the basis of various biological theories of personality, which can explain the differences in some personality traits, different behaviours and reactions. Eysenck's theory is based on empirical data, formed from the results of factor analysis, as well as the results of a large number of experiments. Its hypotheses are based on Hull's behavioural theory of learning, Pavlov's psychoneurology, as well as modern neurology and neurological concepts about the functioning of the nervous system (7). Eysenck strongly advocates that there are three major dimensions in the description of personality: extraversion-introversion, emotional stability-neuroticism and psychoticism, with the most attention and research devoted to extraversion-introversion, while ARASfunctioning comprises the biological basis of this dimension. The ARAS is located in the brainstem and controls the overall level of nerve impulses that enter the cerebral cortex. Introverts demonstrate higher basal levels of cortical arousal because the ARAS misses too many nerve impulses, so they choose an environment with little stimulation. In this way they retain their relatively higher level of arousal under control (8). Eysenck has also assumed greater sociability of extraverts because other people are usually the strongest source of stimulation. Unlike extroverts, introverts may avoid these sources of stimulation and be manifestly unsociable (7). Hebb's notion of optimal level of arousal to perform different tasks or activities was also incorporated in Eysenck's theory. Thus, the characteristics that describe introverts (e.g. quiet, withdrawn) and extraverts (e.g. open, outgoing, assertive) are considered to be attempts to control arousal (lowering in introverts and increasing in extraverts), in order to maintain optimal levels (8). According to Eysenck's theory, extraverts are not easily conditioned, which may lead to poor socialization and a high propensity to engage in risk-taking behaviour. Eysenck has collected results for the biology of this dimension, including evidence that introverts respond better to punishment, while the extraverts respond better to reward (9). Numerous studies have also been aimed at testing Eysenck's settings. If introverts have higher arousal than extroverts, then they should have more pronounced measures of cortical activity, EDR's, etc. However, using various measures of the central nervous, cardiovascular and biochemical systems, it was found that compared to extroverts, introverts have lower levels of arousal in a non-stimulating, resting state (10).

Eysenck associates another dimension, neuroticism-emotional stability, with the reactivity of the autonomic nervous system. 
Individuals with high scores on the neuroticism dimension have lower tolerance for frustration (7). Research shows that they are emotionally labile, anxious and that they complain about various forms of bodily pain (e.g. headaches, digestive disorders, etc.). Their autonomic nervous system also reacts quickly to stress (9). Less is known about the biological basis of psychoticism. Aggressiveness is one of the components of psychoticism, which can be affected by testosterone levels. Eysenck emphasizes that this dimension is polygenetic (11).

Gray's theory (12) is also a biological theory of personality, which assumes the existence of hypothetical systems that determine behaviour. These are the behavioural inhibition system (BIS) and the behavioural approach system (BAS). The BAS system responds to stimuli, such as signs for rewards, and it determines approach behaviour, while the BIS system responds to signs of punishment, frustration and uncertainty. According to Gray, there are differences among individuals in sensitivity of the BIS and BAS systems. Subjects with reactive BIS are sensitive to signs of punishment, frustration and novelty, while subjects with reactive BAS are inclined to approach stimuli, and their ability to stop the behaviour decreases as it approaches the goal. This system is responsible for the dimension of impulsivity and the inability to inhibit responses (13). According to this theory, the BIS is the biological basis of anxiety and BAS is the biological basis of impulsiveness. Highly anxious people, according to Gray's conceptualization, show a higher degree of behavioural inhibition than non-anxious people. Many researchers believe that Gray's constructs are similar to neuroticism and extroversion, in the sense that they relate to dispositional tendencies to retreat before approaching the reward or punishment. Therefore, the differences in sensitivity to reward and punishment lead to different behaviours associated with anxiety/ neuroticism and impulsivity/ extraversion. According to this theory, anxiety is associated with greater sensitivity to signals of punishment, while impulsivity is associated with greater sensitivity to reward signals. These hypotheses have been confirmed in studies on anxious and impulsive subjects (14).

Zuckermann (15) also dealt with the concept of arousal in his sensation seeking theory. Sensation seeking is the dimension of personality that has a biological basis, and implies a preference for seeking exciting activities, taking risks and avoiding boredom. This theory assumes the existence of an optimal level of stimulation for each subject. In order to increase their arousal levels, persons with low levels of arousal seek for stimulation, often in the form of aggressive or other antisocial behavior. Zuckermann (15) found that individuals who are "hungry for excitement" seek sexual sensations and experience to a greater extent than those who do not have this trait expressed. Sensation seeking increases with age, from childhood to adolescence and peaks in late adolescence around ages 18 or 20 (8). Research into teenagers shows the connection between sensation seeking and liberal views on cannabis use and deviant behaviour (16), as well as higher caffeine and nicotine product use in children and adolescents (17). Theoretical explanation of sensation seeking is very similar to Eysenck's explanation for extraversion. There is also a moderate positive correlation between extraversion and this trait of personality (8). According to Zuckermann (15), there is a biological basis for sensation seeking behaviour that includes neurotransmitter systems. MAO is an enzyme responsible for the maintenance of adequate levels of neurotransmitters. High sensation seekers have low levels of MAO in their blood, which could indicate more available neurotransmitters in the neurons. With low levels of MAO, they have less inhibition in the nervous sys- 
tem, and less control over their behaviour, thoughts and emotions (15). Thus, sensation seeking behaviours are not only a consequence of seeking an optimal level of arousal, but also low amounts of MAO in the synapse. Levels of neurotransmitters could also be related to specific individual differences in behaviour. Thus, dopamine is associated with pleasure. Researchers have discovered the role of serotonin in depression and other mood disorders, whereas norepinephrine is associated with activation of the sympathetic nervous system during fight and flight reactions. In the Cloninger's three-dimensional model of personality, three traits are associated with three different neurotransmitter systems. The first trait is Novelty Seeking, which is based on lower levels of dopamine. Another trait, called Harm Avoidance, is associated with variations in the metabolism of serotonin, while Cloninger associates Reward Dependence with low levels of norepinephrine (18). Personality models based on just one neurotransmitter system have obviously been simplified (9). In addition, it is hard to integrate all neurobiological findings in a model with three dimensions, due to the risk of simplifying many of the discovered neurobiological insights.

\section{Personality traits in studies of violence among children and adolescents}

Antisocial behaviour in children and adolescents can be operationalized in terms of psychiatric diagnosis (behaviour disorder, conduct disorder, etc.), violations of social norms (delinquency, criminality) or aggressive behaviour (4). Eysenck's antisocial behaviour hypothesis predicts that high psychoticism, extraversion and neuroticism, in combination with a low score on the lie scale (L) of Eysenck's questionnaires, is a profile that increases the risk for antisocial behaviour. Extraversion increases risk due to low cortical activation, whereas high neuroticism adds the emotional and irrational character of antisocial behaviour, which leads to over reactions (11). Psychoticism includes several traits that increase the risk of antisocial behaviour: impulsivity, cruelty, conformism, hatred, hostility, lack of empathy (19). A low score on the L scale is usually interpreted as an indication of poor socialization (11). In Eysenck questionnaires, the results on the $\mathrm{L}$ scale are interpreted in terms of social dissimulation, as well as a stable personality factor that indicates social naivety or conformity. Previous studies have not fully confirmed Eysenck's hypothesis about antisocial behaviour. Individually, each of these personality traits independently can contribute to antisocial behaviour. In a sample of high-risk children aged from 11 to 17, three different measures of antisocial behaviour were used (physical aggression, theft and vandalism). It was found that all forms of antisocial behaviour were associated with a specific personality. Some characteristics of extraversion (energy and venturesomeness) are associated with physical aggression. High venturesomeness is associated with persistent vandalism and theft, while psychotic features (low empathy and impulsivity) are associated with physical aggression or vandalism, but not with a propensity towards theft (20). Bullying is also a form of antisocial behaviour. A smaller number of studies have examined the differences in Eysenck's personality dimensions in children, considering their role in peer violence (21). As expected, a higher dimension of psychoticism was obtained for boys, while girls showed higher levels of social dissimulation and neuroticism. Bullies in this study had above average levels of extraversion and psychoticism, and average levels of neuroticism, which is in line with Eysenk's hypothesis. For the role of a bully/victim, which is characterized by the personality of both the victim and the bully, higher levels of extra- 
version, psychoticism and neuroticism and lower dissimulation were obtained, while the victims had also higher levels of neuroticism and tendency for dissimulation (21). Impulsivity, as well as the combination of high impulsivity and low anxiety, also increases the risk of antisocial behaviour (20). Impulsive children tend to show a form of sensation seeking behaviour (20). Aggression, conduct problems and criminal behaviours are also present in children with a high degree of fearlessness (22). When it comes to the Big Five personality traits model, it was found that bullies show lower results for agreeableness and conscientiousness. Their personality profile is characterized by hostility, antisocial and impulsive pulses, low levels of guilt, and increased arousal while talking about their experiences of abuse (23). Victimization, in turn, is in relation to low conscientiousness and higher neuroticism. The combination of low conscientiousness and high neuroticism in the victims can result in an inability to control behaviour in conflict situations and reactions that can only worsen the situation of violence (23). One interesting study (19) has shown that subjects with high psychoticism prefer watching violent videos, while subjects with low psychoticism prefer watching comic content. Psychotic subjects evaluated violent content as more enjoyable and comical than comic content. EDR showed rapid habituation when watching violent content in psychotic subjects, while the low-psychotic showed greater physiological sensitivity. Somewhat different results were obtained using other measures of arousal, based on different theoretical settings. The advantage of Coren's Arousal Predisposition Scale, as a stable measure of an individual's traits of arousal, is unidimensionality and its significant correlation with physiological measures (EDR and electromyographic answers) $(5,6)$. Some previous studies have included the application of this scale in re- search on bullying, respecting the role of children in violent behaviour. Researchers report a higher level of arousal in bullies and victims in relation to children who are not involved in violence (24). Similar results were obtained in some other studies (25). Examining the level of arousal in $457 \mathrm{fifth}$ graders and 421 eighth grade students, the highest level of arousal was observed in victims/bullies (25). The high levels of arousal in this group could be explained by their increased anxiety. This role indicates an unstable personality, which includes anxiety abuser and provocative victim (24). The higher level of arousal in the victims could also be associated with shyness, avoidant behavior, but also with heightened anxiety.

The past decade has been characterized by an increase in interest in a variety of behavioural problems in childhood and adolescence, and the increased arousal in participants in the violence could also be associated with a variety of psychological difficulties. Children with high levels of arousal also have high sensitivity to signals of punishment and non-reward, which can result in numerous changes in behaviour, that can manifest as emotional problems, anxiety, shyness, inhibitory and avoidable behaviours (24). High levels of arousal on Coren's scale are also the most significant predictor of internalizing and externalizing psychological difficulties in primary school children (24). These results could be partially explained by personality and partially by coping strategies, as well as the behavioural difficulties of the participants of violence. These studies have shown that it is difficult to draw clear conclusions about the causes and consequences of violent behaviour. Therefore, in future studies, which include Coren's measure of arousal, preference should be given to longitudinal studies. Studies of the relationship between Coren's measures and other measures arising from biological theories of personality are lacking. One study has been found to be positively 
correlated with Eysenck's neuroticism and it is possible that Coren's measure examines the level of autonomic arousal (5), which should be tested in further research. On the basis of previous research and the theoretical assumptions presented it can be said that some personality traits may increase the risk for violence in children and adolescents. However, these traits should be seen as the potential for the development of certain forms of behaviour. Aggressiveness and different forms of violence can be predicted with more confidence if certain characteristics of personalities in children appear simultaneously with dysfunctional families, conflicts, psychological distress of parents, etc. (22). Interest in the role of neurobiological processes in the psychopathology of children has increased in recent years.

\section{Neurobiology of violence in children and adolescents}

In the past, the question about centre of the violent behavior was often asked, as well as whether such behaviour can be inhibited or moderated. Today we know that there is not only one such centre (26). Progress in neuroanatomy and diagnostic methods has led to the notion that aggressive behaviour relates to the interaction between different areas of the nervous system. Today, much is known about the parts of the nervous system responsible for certain functions. For example, the limbic system is important in the processing of emotional stimuli. As a major part of this system, the amygdala plays a central role in fear conditioning, and emotionally charged memories. There is also evidence that the sensitivity of the amygdala plays a key role in high levels of anxiety and agitation (9). The frontal lobe and its dysfunction have long been associated with antisocial behaviour (27). Regions of the prefrontal cortex are responsible for executive functions such as impulse control, reasoning, and decision making (28). People with lesions of the frontal cortex show changes in emotionality and personality, which include a higher level of reactive, but not instrumental aggression (27). In children with callous-unemotional traits, reduced connections between the amygdala and ventromedial prefrontal cortex are presented, which can explain the occurrence of reactive and proactive aggression (29). Dysfunction of the orbital and medial frontal cortex also increases the risk of antisocial behavior (27). Reactions that involve the regulation of affective impulses and inappropriate expressions of anger are associated with the functions of the limbic system and also dysfunction in areas of the brain responsible for decision-making (29). Atypical and abnormal EEG patterns were found in psychopathic personality traits, as well as in children with behavioural disorders. One of the most commonly observed EEG abnormalities is a predominance of slow wave activity (30). Studies of the etiology of violence have been more focused on the adverse environmental impacts, such as economic problems, parental pathology, physical abuse, etc., which can also reflect genetic influences. Meta analytic studies cited by some authors (4) conclude that genes affect antisocial behaviour by $40-50 \%$, and that this percentage is higher in the case of aggression. However, early brain development during the prenatal and postnatal period is particularly sensitive to different adverse environmental impacts (4) which should be taken into consideration when interpreting the results obtained in studies of violence. Atrophy of neurons in the right hemisphere, and the reduction of the volume of the hippocampus, which is important in verbal and emotional memories, is influenced by childhood trauma (28). Some neurobiological factors may also explain the persistence of violent behaviour (4). Testosterone levels, serotonergic system and mechanisms, which include the HPA 
axis and autonomic nervous system, play an important role in violent behaviour in children and adolescents.

\section{Testosterone and violence in children and adolescents}

Aggression, as well as various forms of violent behavior, is associated with the male gender. In most animal species, males are also more aggressive than females. The prevalence of antisocial behaviour is also higher among men offenders (26). The increased presence of violent behaviour in men could be explained in several ways: less fear and empathy, higher impulsivity and anger, greater physical strength, and higher levels of testosterone. Hormonal influences on behaviour may be activational and organizational, which implies structural changes occurring in the prenatal and perinatal development (31). Testosterone has been the most investigated hormone in the context of antisocial behaviour. Researchers analyzed the level of this hormone in serum or saliva and found a significant association with aggressive and criminal behaviour (26). Circulating testosterone consistently shows positive links with antisocial behaviour in childhood, adolescence and adulthood (32). Its ability of facilitation of aggressive behaviour has also been documented in a number of mammals (31). Taking into account the dramatic hormonal changes that occur during puberty, studying the relationship between testosterone and aggression is not surprising. The process of biological maturation is slower in boys than in girls. Brain imaging studies have shown that the total volume of the brain in girls reaches its peak four years earlier than in boys. Girls also enter puberty 18-24 months earlier than boys. Although the biological mechanisms that cause these differences in maturation are not yet fully known, testosterone could be one of the mechanisms (31). However, in the preschool period, levels of androgen hormones secreted by the adrenal glands are low in both boys and girls. In a study of preschool children salivary testosterone was measured and the children's interactions during free play were videotaped. The results showed a positive correlation between testosterone and giving and receiving aggression in the context of social interaction (serious aggression), but not in the context of play (playful aggression). This study has shown that testosterone can be a useful biological marker of aggression in preschool children (33). Scores for irritability and resentment using the BussDurkee Hostility Inventory were also positively correlated with levels of testosterone, as well as some other hormones (norepinefrine and cortisol levels) (34). Apart from this, testosterone is associated with social dominance (4) and an increased reaction to provocation (31). Studies have reported an increase in the testosterone levels in male fans when their team wins, as well as a reduction when they lose (31). This hormone is a useful marker for identifying children at risk for disruptive disorders. Its elevated levels were recorded for boys aged from 9-11 with behavioural disorders (35). In a study of intelligence, it was found that testosterone explains $16 \%$ of the variance in aggression, and 36\% of the variance in social withdrawal. In older boys it is in relation to delinquency, aggression and withdrawal, while in younger ones it is only significantly associated with lower involvement in social activities (35). This study also showed that the relationship between testosterone and both aggression and withdrawal, is moderated by intelligence. Despite numerous studies, aggressive and violent behaviour cannot be fully explained by testosterone levels. Some of the biopsychosocial factors that modulate the relationship between testosterone levels and aggressive behaviour are the HPA axis and serotonergic mechanisms. In their theoretical model, whose settings 
derived from present knowledge about the relationship between biological processes and antisocial behaviour, Yildirim and Derksen (32) emphasize that testosterone levels in interaction with other biological and social factors, are a risk factor for antisocial behaviour. Based on previous research it has been shown that positive social experiences are protective factors in antisocial behaviour. In individuals with high testosterone, these experiences could result in the development of desirable social characteristics as well as leadership, motivation for competitive achievements, social assertiveness, etc.

\section{Stress-regulating mechanisms and antisocial behaviour in children and adolescents}

Stress-regulating mechanisms, including the HPA axis and autonomic nervous system are also the starting points for explaining violent behaviour. In relation to the HPA axis, its activation results in increased secretion of corticotropin-releasing hormones in the paraventricular nuclei of the hypothalamus $_{2}$ stimulating the anterior pituitary to increased secretion of adrenocorticotropic hormone. This hormone in turn stimulates the adrenal glands to increased production of corticosteroids. The most important glucocorticosteroid in baboons and humans is cortisol, which is known as the stress hormone. Numerous studies have included measurements of cortisol in plasma or serum as a final product activity of the HPA axis. In children, the HPA system reaches functional maturity by the age of 4 (4), while meta analytic studies show that low levels of cortisol predict antisocial behaviour (36). According to the sensation seeking theory, antisocial children could look for stressful situations in order to increase their low levels of cortisol. However, on the basis of previous studies, it is not possible to make conclusions about the cause-consequent relations between low cortisol and aggressive behaviour. The connection between the HPA axis functioning and antisocial behaviour can vary depending on the type of antisocial behaviour, patterns of comorbidity and early unfavourable environmental events (24). Longitudinal studies show that low morning cortisol levels predict disruptive behaviour symptoms in preadolescence. Studies also report the relationship between the dysfunction of the HPA axis and various externalized disorders in children (4). The highest incidence of disruptive disorders is to be expected in boys, due to the fact that they have lower morning cortisol than girls (36). Furthermore, shy children have high levels of cortisol, which could indicate higher levels of perceived stress (8), while callousunemotional traits in children are associated with low levels of cortisol (36). Although it is possible that genetic factors are of great importance in the functioning of the HPA axis, a number of studies show that abuse and neglect in the early years of life is of considerable importance in the functioning of this system later. Traumatic stress results in a series of neurobiological changes that may sensitize children to aggression and other forms of antisocial behaviour (28). There are also links between childhood abuse and abnormalities in the cingulate cortex and corpus callosum (4) and EEG abnormalities in the frontal and temporal regions of the left hemisphere (28). Low levels of cortisol cannot entirely explain the different forms of antisocial behaviour in children and adolescents. However, the occurrence of such studies has increased the interest in the moderators of the relationship between the functioning of the HPA axis and antisocial behaviour. Previous studies have shown that their relationship can be modulated by personality traits, on the one hand, and early adverse environmental impacts on the other. 


\section{Autonomic arousal and violence in children and adolescents}

Heart rate and EDR are frequently used measures of the autonomic arousal system in perpetrators of violence. While heart rate reflects sympathetic and parasympathetic activity, EDR reflects only sympathetic activity. Some authors associate higher EDR with fear and anxiety and, in general, stronger emotional responses (37). The use of respiratory sinus arrhythmia (RSA) was proposed, which gives insight into parasympathetic activity. Lower basal RSA in perpetrators of violence could also be interpreted as an inability to control emotions, and flexible adaptation to environmental demands (37). A widely cited longitudinal study (38) showed that a lower basal heart rate in three-year-old children predicted their aggressive behaviour at age 11. The results of a recent meta analytic study also show that heart rate at rest is the best marker of antisocial and aggressive behaviour during childhood and adolescence, with an average effect size of -0.44 obtained from a total of 40 independent studies on a sample of 5868 children (39). Heart rate during stress is also associated with antisocial behaviour in the same direction. However, variables such as gender, age, intelligence, weight, height, etc. do not moderate the relationship between heart rate and antisocial behaviour in children (39). As a predictor of antisocial behavior, lower heart rate is also independent from the influence of other family risk factors (40). It should be said that lower heart rate is hereditary. Parents with criminal records have a lower heart rate, which is also found in their offspring (40). Men have a lower heart rate than women (41), which may, at least partially, explain their higher involvement in antisocial behaviors. There are two main interpretations of reduced autonomic activation in antisocial behaviour. According to the fearlessness theory, low arousal is a marker of fearlessness (4). Fearless children engage in physical violence in order to gain reward and social status, and in doing so, they do not concentrate on the negative consequences of their behaviour (punishment, physical injury). According to the theory of sensation seeking, violent behaviour increases the level of arousal to the optimal or normal level (15). Biological processes that might mediate in the relations of low heart rate and antisocial behaviour include dysfunction of the right hemisphere, reduced noradrenergic functioning and increased vagal tone (42). Another current hypothesis (40) assumes that the relationship between low heart rate and violent behaviour stems from prefrontal deficits, caused by trauma, childbirth complications, maternal smoking, etc. It can result in inappropriate decision-making and deficits of learning from experience. The author states that the brain injury, caused by these adverse factors, leads to deficits in the prefrontal cortex and autonomic changes (lower heart rate) at the same time. Retinoid toxicity hypothesis is also offered in interpreting the relationship between low heart rate and antisocial behaviour. Retinoids (vitamin $\mathrm{A}$ and its congeners) play an important role in embryogenesis and neural development, passing the blood-brain barrier. They are involved in the development of the central nervous system. Retionid receptors are also distributed in the areas of the brain that are important in aggressive behaviour (amygdala, prefrontal cortex, hypothalamus, hippocampus), and affect the monoamine neurotransmitter systems (40). According to this hypothesis, retinoid overexpression in utero, via noradrenergic and cholinergic pathways, induces changes in cardiac function and hemodynamics, resulting in a lower heart rate, and structural and functional changes in the cortex and persistent aggression (40). Other studies also indicate an association between lower heart rate and externalizing problems, and higher heart rate and internalizing problems in adolescents (43). 
EDR is also a reliable correlate of aggression, and it is interpreted as a reflection of the poor BIS system (44). Lower EDR is associated with low anxiety and impulsivity, as well as deficit controls of emotional expression (44). During the presentation of various scenes, EDR measuring showed that children with psychopathic tendencies had weaker autonomic reactivity to the suffering of other people (27). These children have been identified as being unable to recognize other people's sad facial expressions and poorer recognition of fear (27). Previous studies have confirmed a link between low autonomic arousal and violent behaviour. Future research will need to offer additional information on potential mediators and/or moderators of this relationship.

\section{Neurotransmitter systems and violence in children and adolescents}

Without knowledge of the role of the neurotransmitters that are involved in communication between neurons we cannot fully understand aggressive behaviour. A number of previous studies have indicated that monoamines, including serotonin, norepinephrine and dopamine, are connected with violent behaviour (4). Serotonin is a widely distributed neurotransmitter in the brain, with a high density of receptors in the prefrontal cortex. It appeared early in evolution and is involved in many biological processes, including learning and memory, mood regulation, food intake, sleep, play, circadian rhythms and social behaviour (41). It has long been associated with aggressiveness (particularly reactive) and impulsivity. Studies on primates also show that a deficit in serotonergic activities is associated with impulsive and aggressive behaviour (26). Zuckerman (15) also emphasizes that antisocial behaviour in psychotic subjects is in relation to deficits in the serotonergic and noradrenergic system, which facilitates behavioural disinhibition, impulsivity and sensation seeking behaviour. Low MAO activity is also related to aggressiveness, while the interaction of serotonin and this enzyme with experiences in early childhood increases the risk of antisocial behaviour in adulthood $(15,41)$. There is also an interaction between serotonergic and the HPA axis (28). In recent decades, sleep disorders have also been associated with aggressive behaviour in children. Shorter total sleep time in seven-year-old children is associated with problematic behaviour, while the ability to recognize facial expressions of anger and happiness was reduced after sleep deprivation (45). It is also possible that some children are more vulnerable to reduced sleep. The links between sleep disorders and aggression may be stronger in impulsive children.

\section{Conclusion}

Different neurobiological systems, especially the HPA axis and the autonomous system, testosterone and the serotonergic system are involved in the occurrence of antisocial behaviour. Some authors (4) propose a theoretical model of etiological factors of violent behaviour, in which, in the relationship between various adverse factors (genetic influences, early difficulties in childhood) and violent behaviour, neurobiological systems, discussed in this paper, have been positioned as a mediator variable. Therefore, their role is certainly to be studied in interaction with environmental factors. Better understanding of different neurobiological processes should contribute to prevention as well as the opening of new possibilities of treatment of violent behavior in children and adolescents. To that end, priority should be given to longitudinal studies. Although individual differences in biological processes are generally stable, the possibility of change influenced by experience must not be forgotten. We need to learn 
a great deal about the plasticity of neurobiological functioning. Until then, the normal functioning of the HPA axis, testosterone levels and serotonergic mechanisms, as well as higher autonomic reactivity in children are protective factors that provide a greater degree of self-control in their behaviour.

Conflict of interest: The author declare that she has no conflict of interest.

\section{References}

1. French WP. Neurobiology of violence and victimization. In: Miller TW., editor. School violence and primary prevention. New York: Springer; 2008. p. $25-58$

2. Viding E, Larsson H. Aetiology of antisocial behaviour. International Congress Series. 2007;1304:121-132.

3. Loeber R, Pardini D. Neurobiology and the development of violence: common assumptions and controversies. Philos Trans R Soc Lond B Biol Sci. 2008;363:2491-503.

4. van Goozen SHM, Fairchild G, Snoek H, Harold G. The evidence for a neurobiological model of childhood antisocial behavior. Psychol Bull. 2007;133(1):149-82.

5. Šimić N, Sesar K, Barišić M. Arousal Predisposition Scale. In: Proroković A, Cubela Adorić V, Penezić Z, Tucak Junaković I, editors. Collection of psychological scales and questionnaires [in Croatian]. Zadar: Sveučilište u Zadru; 2012. p. 37-43.

6. Coren S. Arousal predisposition as a predictor of antisocial and delinquent behavior. Pers Indiv Differ. 1999;27:815-20.

7. Fulgosi A. Biological basis of personality [in Croatian]. Jasrebarsko: Naklada Slap; 1994.

8. Larsen RJ, Buss DM. Psychology of personality [in Croatian]. Jasrebarsko: Naklada Slap; 2008.

9. Pervin LA, Cervone D, John OP. Psychology of personality: theories and research [in Croatian]. Zagreb: Školska knjiga; 2008.

10. Stemmler G, Wacker J. Personality, emotion, and individual differences in physiological responses. Biol Psychol. 2010;84:541-51.

11. Center DB, Jackson N, Kemp D. A test of Eysenck's antisocial behavior hypothesis employing 11-15-year old students dichotomous for PEN and L. Pers Indiv Differ. 2005;38:395-402.
12. Gray JA, McNaughton N. The neuropsychology of anxiety. An enquiry into the functions of the septohippocampal system. Oxford: University Press; 2003.

13. Corr PJ, Perkins AM. The role of theory in the psychophysiology of personality: from Ivan Pavlov to Jeffrey Gray. Int J Psychophysiol. 2006;62:367-76.

14. De Pascalis V, Strippoli E, Riccardi P, Vergari F. Personality, event-related potential (ERP) and heart rate (HR) in emotional word processing. Pers Indiv Differ. 2004;36:873-91.

15. Zuckerman M. Psychobiology of personality. Cambridge: University Press; 2005.

16. Stephenson MT, Hoyle RH, Palmgreen P, Slater MD. Brief measures of sensation seeking for screening and large-scale surveys. Drug Alcohol Depend. 2003;72: 279-86.

17. Gurpegui M, Jurado D, Luna JD, FernandezMolina C, Moreno-Abril O, Galvez R. Personality traits associated with caffeine intake and smoking. Prog Neuropsychopharmacol Biol Psychiatry. 2007;31:997-1005.

18. Stewart ME, Ebmeier KP, Deary IJ. The structure of Cloninger's Tridimensional personality questionnaire in a British sample. Pers Individ Differ. 2004;36:1403-18.

19. Bruggemann J, Barry RJ. Eysenck's P as a modulator of affective and eletrodermal responses to violent and comic film. Pers Indiv Differ. 2002;32:1029-48.

20. Carrasco M, Barker ED, Tremblay RE, Vitaro F. Eysenck's personality dimensions as predictors of male adolescent trajectories of physical aggression, theft and vandalism. Pers Indiv Differ. 2006;41:1309-20.

21. Sesar K, Šimić N, Barišić M. Roles in bullying behavior and Eysenck's personality dimensions in elementary school children. Paediatrics Today. 2011;7(1):26-36.

22. Essau C.A, Conradt J. Aggressiveness in children and adolescents [in Croatian]. 2. izdanje. Jastrebarsko: Naklada Slap; 2009.

23. Bollmer JM, Harris MJ, Milich R. Reactions to bullying and peer victimization: narratives, physiological arousal and personality. J Res Pers. 2006;40:803-28.

24. Sesar K. Violence in the elementary school: Relationship between arousal level, roles in bullying behavior, coping strategies and psychological adjustment [dissertation]. Sarajevo: Univerzitet $\mathrm{u}$ Sarajevu; 2010. 
25. Sesar K, Šimić N, Barišić M. Differences in arousal level in participants of different roles in bullying behavior. In: Kolenović-Đapo J, Fako I, KosoDrljević M, Mirković B., editors. Zbornik radova sa Drugog Kongresa psihologa Bosne i Hercegovine sa međunarodnim učešćem; 2011, Septembar, Banja Luka, Bosna i Hercegovina, 229-243.

26. Kocijan-Hercigonja D. Neurobiology of agression. In: Faber B, Folnegović-Šmalc, Gotovac K, Heningsberg N, Hercigonja-Novković, KocijanHercigonja D. et al., editors. Biological basis and therapy of behavior [in Croatian]. Zagreb: Školska knjiga; 2006. p. 117-125.

27. Blair J, Mitchell D, Blair K. Psychopath. Emotion and brain [in Croatian]. Jastrebarsko: Naklada Slap; 2005.

28. Heide KM, Solomon EP. Biology, childhood trauma and murder: rethinking justice. Int J Law Psychiat. 2006; 29:220-33.

29. Jones AP, Laurens K, Herba C, Barker GJ, Viding E. Amygdala hypoactivity to fearful faces in boys with conduct problems and callous-unemotional traits. Am J Psychiatry. 2009;166:95-102.

30. Reyes AC, Amador AA. Qualitative and quantitative EEG abnormalities in violent offenders with antisocial personality disorder. J Forensic Legal Med. 2009;16:59-63.

31. Ramirez JM. Hormones and aggression in childhood and adolescence. Agress Violent Beh. 2003;621-44.

32. Yildirim BO, Derksen JJL. A review on the relationship between testosterone and life-course persistent antisocial behavior. Psychiatry Res. 2012;200:984-1010.

33. Sanchez-Martin JR, Fano E, Ahedo L, Cardas J, Brain PF, Azpiroz A. Relating testosterone levels and free play social behavior in male and female preschool children. Psychoneuroendocrinology. 2000;25:773-83.

34. Gerra G, Avanzini P, Zaimovic A, Fertonani G, Caccavari R, Delsignore R, et al. Neurotransmitter and endocrine modulation of aggressive behav- ior and its components in normal humans. Behav Brain Res. 1996;81:19-24.

35. Chance SE, Brown RT, Dabbs JM, Casey R. Testosterone, inteligence and behavior disorders in young boys. Pers Indiv Differ. 2000;28:437-445.

36. Hawes DJ, Brennan J, Dadds MR. Cortisol, callous-unemotional traits, and pathways to antisocial behavior. Curr Opin Psychiatry. 2009;22:357-62.

37. Murray-Close D, Holland AS, Roisman GI. Autonomic arousal and relational aggression in heterosexual dating couples. Personal Relationships. 2012;19(2):203-18.

38. Raine A, Venables PH, Mednick SA. Low resting heart rate at age 3 years predisposes to aggression at age 11 years: Evidence from the Mauritus Child Health Project. J Am Acad Child Adolesc Psychiatry. 1997;36:1457-64.

39. Ortiz J, Raine AD. Heart rate and antisocial behavior in children and adolescents: a meta analysis. J Am Acad Child Adolesc Psychiatry. 2004; 43(2):154-62.

40. Mawson AR. On the association between low resting heart rate and chronic aggression: retinoid toxicity hypothesis. Prog Neuropsychopharmacol Biol Psychiatry. 2009;33:205-13.

41. Susman EJ. Psychobiology of persistent antisocial behavior: stress, early vulnerabilities and the attenuation hypothesis. Neurosci Biobehav Rev. 2006;30 376-89.

42. Armstrong TA, Boutwell BB. Low resting heart rate and rational choice: integrating biological correlates of crime in criminological theories. Journal of Criminal Justice. 2012;40:31-9.

43. Oldehinkel AJ, Verhulst FC, Ormel J. Low heart rate: a marker of stress resilience. The TRAILS study. Biol Psychiatry. 2008;63:1141-46.

44. Fowles DC. Electrodermal hyporeactivity and antisocial behavior: does anxiety mediate the relationship? J Affect Disord. 2000;61:177-89.

45. Kamphuis J, Meerlo P, Koolhaas JM, Lancel M. Poor sleep as a potential causal factor in aggression and violence. Sleep Med. 2012;13:327-34. 